\title{
XXXV INTERNATIONAL ASTIN COLLOQUIUM \\ Sunday June 6 to Wednesday June 9, 2004
}

The $35^{\text {th }}$ International ASTIN Colloquium will be held in Bergen, Norway. The Norwegian Actuarial Society extends its most sincere welcome to all participants and partners to join us in what will surely become days full of meaning both professionally and socially.

\section{Call for papers}

We invite authors to submit papers on any subject covered by ASTIN; see the "Call for papers" entry on the website. Deadline for submitting scientific papers in their final form: February 1, 2004.

\section{Scientific Program committee}

Erik Bølviken (chairman), Paul Embrechts, Simen Gaarder, Angus MacDonald, Ragnar Nordberg, Mette Rytgaard.

\section{Key notes lectures}

Opening by prominent actuary in the insurance industry.

Closing by prominent academic on actuarial science in $21^{\text {th }}$ century.

\section{Organized sessions}

Thematic sessions have been organized on

Insurance fraud

Genetics and insurance

Climatic change and its impact on insurance

Coordinated lectures will be given by actuaries and by relevant people from the outside. Details: See conference website

\section{Conference venue}

The colloquium will take place in Bergen (Norway's second largest city), located on the west coast at the entry of magnificent fjords and waterfalls. The town, still marked by its hanseatic origin, was for centuries the commercial capital of the country. Today Bergen is the bustling home of two universities, and became a European city of culture three years ago. Karl Borch, co-founder of modern risk theory, resided here.

\section{www.astin2004.no}

The website gives you up-to-date information. Here you will find the preregistration schedule. 